\title{
Carvedilol reduced mortality and morbidity caused by myocardial infarction in patients with left ventricular dysfunction
}

The CAPRICORN Investigators. Effect of carvedilol on outcome after myocardial infarction in patients with
left-ventricular dysfunction: the CAPRICORN randomised trial. Lancet 2001 May 5;357:1385-90.

QUESTION: In patients with left ventricular dysfunction, does adding carvedilol to the
management of myocardial infarction (MI) reduce mortality and non-fatal MI?
Sources of funding:

Glaxo SmithKline and

Roche

Pharmaceuticals.

For correspondence: Professor H J Dargie, Department of Cardiology, Western Infirmary, Glasgow G11 2NT, Scotland, UK. Fax $+44(0) 141$ 2111791.

\section{Design}

Randomised \{allocation concealed $*\}$, blinded (patients, judicial assessors of outcomes, data analysts), ${ }^{*}$ placebo controlled trial with a mean 1.3 years of follow up.

\section{Setting}

163 centres in 17 countries.

\section{Patients}

1959 patients (mean age $63 \mathrm{y}, 74 \%$ men) participated. Inclusion criteria were age $>18$ years; stable and definite MI occurring 3 to 21 days before randomisation; left ventricular ejection fraction $\leqslant 0.40$; wallmotion-score index $\leqslant 1.3$; current treatment with angiotensin-converting enzyme (ACE) inhibitors for $\geqslant 48$ hours with a stable dose for $\geqslant 24$ hours; and if the patient was having heart failure treatment with diuretics and ACE inhibitors. Exclusion criteria included uncontrolled heart failure, unstable angina, and need for intravenous diuretics or inotropes. Follow up was $100 \%$.

\section{Intervention}

975 patients were allocated to carvedilol and 984 to the placebo group. Patients initially received $6.25 \mathrm{mg}$ carvedilol twice daily; the dose was titrated to a maximum of $25 \mathrm{mg}$ twice daily. Treatment was reviewed every 3 months for the first year and every 4 months thereafter until the study ended, at which time medication was withdrawn over 1 to 2 weeks.

\section{Main outcome measures}

All-cause mortality, cardiovascular mortality, non-fatal MI, and all-cause mortality or non-fatal MI.

\section{Main results}

Analysis was by intention to treat. All-cause and cardiovascular mortality and non-fatal MI were lower in the carvedilol group than in the placebo group (table).

\section{Conclusion}

Adding carvedilol to the short term management of myocardial infarction (MI) reduced all-cause and cardiovascular mortality and non-fatal MI in patients with left ventricular dysfunction.

*See glossary.

$\dagger$ Information provided by author.
Carvedilol v placebo in acute management of myocardial infarction (MI) at a mean of 1.3 years $\ddagger$

\begin{tabular}{lcccc} 
Outcomes & Carvedilol & Placebo & RRR (95\% CI) & NNT (CI) \\
All-cause mortality & $12 \%$ & $15 \%$ & $22 \%(3$ to 38$)$ & 30 (16 to 244$)$ \\
\hline Cardiovascular mortality & $11 \%$ & $14 \%$ & $24 \%(4$ to 40$)$ & $29(16$ to 185$)$ \\
\hline Non-fatal MI & $3 \%$ & $6 \%$ & $40 \%(9$ to 60$)$ & 44 (24 to 223$)$ \\
\hline $\begin{array}{l}\text { All-cause mortality or } \\
\text { non-fatal MI }\end{array}$ & $14 \%$ & $20 \%$ & $27 \%(11$ to 40$)$ & 20 (12 to 52$)$ \\
\hline
\end{tabular}

$\ddagger$ Abbreviations defined in glossary; RRR, NNT, and $\mathrm{Cl}$ calculated from data in article.

\section{COMMENTARY}

Determining optimum medical management of patients who have had acute MI has been advancing through a series of randomised controlled trials. Such agents and interventions as aspirin, thrombolytics, $\beta$-blockers, ACE inhibitors, and percutaneous transluminal coronary angioplasty have been systematically studied in this setting. Although the current study by the CAPRICORN investigators shows that a clinical benefit existed in patients who were treated with carvedilol after acute MI with left ventricular dysfunction, some of the study's statistical aspects, such as changing the primary end point during the course of the trial, may affect its approval for this indication. ${ }^{1}$ In fact, enrollment for this trial was impeded in several countries because of the considered-to-be established benefits of $\beta$-blocker treatment after acute MI, especially in high risk patients. For example, most of the mortality benefit of $\beta$-blockade in the $\beta$-Blocker Heart Attack Trial (BHAT) $)^{2}$ was seen in the "high risk" groups, such as patients with heart failure. Similarly, the Survival and Ventricular Enlargement (SAVE) trial data ${ }^{3}$ showed that the benefits of $\beta$-blockade were seen in addition to ACE inhibitor treatment.

How should this trial alter current management? The intuitive answer is that it should not alter but should strengthen current treatment. A sound therapeutic approach would ensure that all patients with acute MI receive aspirin, some form of immediate revascularisation (pharmacological or non-pharmacological), and $\beta$-blockers. At the time of discharge, all eligible patients should receive ACE inhibitors and a statin in addition to aspirin and $\beta$-blockers.

This study highlights the fact that future trials of acute MI cannot ethically withhold $\beta$-blocker treatment. Furthermore, the beneficial effects may be a "class effect" and until such trials as the Carvedilol and Metoprolol European Trial ${ }^{4}$ are completed, insufficient data exist to choose a particular $\beta$-blocker in the clinical setting.

Dinesh H Jagasia, MD Kalyanam Shivkumar, MD, PhD University of Iowa Hospitals and Clinics Iowa City, Iowa, USA

1 Coats AJ. CAPRICORN: a story of alpha allocation and beta-blockers in left ventricular dysfunction post-MI. Int J Cardiol 2001;78:109-13.

2 Chadda K, Goldstein S, Byington R, et al. Effect of propranolol after acute myocardial infarction in patients with congestive heart failure. Circulation 1986;73:503-10.

3 Vantrimpont P, Rouleau JL, Wun CC, et al. Additive beneficial effects of beta-blockers to angiotensin-converting enzyme inhibitors in the Survival and Ventricular Enlargement (SAVE) Study. SAVE Investigators. J Am Coll Cardiol 1997;29:229-36.

4 Krum H. Beta-blockers in heart failure. The "new wave" of clinical trials. Drugs 1999; 58:203-10. 